\title{
Nurse-patient collaboration: A grounded theory study of patients with chronic obstructive pulmonary disease on non-invasive ventilation ${ }^{\text {is }}$
}

\author{
Dorthe Sørensen ${ }^{\mathrm{a}, *}$, Kirsten Frederiksen ${ }^{\mathrm{a}}$, Thorbjoern Groefte ${ }^{\mathrm{b}}$, Kirsten Lomborg ${ }^{\mathrm{a}}$ \\ ${ }^{a}$ Section for Nursing, Department of Public Health, Aarhus University, Denmark \\ ${ }^{\mathrm{b}}$ Department of Anesthesiology, Region Hospital Randers, Denmark
}

\section{A R T I C L E I N F O}

Article history:

Received 30 January 2012

Received in revised form 21 August 2012

Accepted 21 August 2012

\section{Keywords:}

Non-invasive ventilation

COPD

Nurse-patient collaboration

Grounded theory

Nursing

Treatment failure

\begin{abstract}
A B S T R A C T
Objectives: This paper provides a theoretical account of nurses' collaboration with patients with chronic obstructive pulmonary disease during non-invasive ventilation treatment in hospital.

Background: Despite strong evidence for the effect of non-invasive ventilation treatment, success remains a huge challenge. Nurse-patient collaboration may be vital for treatment tolerance and success. A better understanding of how nurses and patients collaborate during non-invasive ventilation may therefore contribute to improvement in treatment success. Design: A constant comparative classical grounded theory.

Method: The data comprised sessions of qualitative participant observation during the treatment of 21 patients with non-invasive ventilation that included informal conversations with the nurses and semi-structured interviews with 11 patients after treatment completion. Data were collected at three intensive care units and one general respiratory ward in Denmark.

Results: Succeeding emerged as the nurses' main concern in the nurse-patient collaboration during non-invasive ventilation treatment. Four collaborative typologies emerged as processing their main concern: (1) twofold oriented collaboration; (2) well-being oriented collaboration; (3) outcome oriented collaboration; and (4) absent collaboration.

Conclusions: This study offers a theoretical account of nurses' main concern and how they activate different ways of collaboration to achieve successful treatment. We offer a theoretical basis for developing complex interventions.
\end{abstract}

(c) 2012 Elsevier Ltd. All rights reserved.

\section{What is already known about this topic?}

- Non-invasive ventilation is first-line treatment for patients with chronic obstructive pulmonary disease admitted to the hospital with acute respiratory failure.

\footnotetext{
This paper was submitted as an entry for the European Academy of Nursing Science's Rosemary Crow award, sponsored by the International Journal of Nursing Studies. The award is open to current doctoral students or recent graduates of the academy's programme.

* Corresponding author. Tel.: +45 21490764.

E-mail addresses: ds@sygeplejevid.au.dk (D. Sørensen), kf@sygeplejevid.au.dk (K. Frederiksen), thorgroe@rm.dk (T. Groefte), kl@sygeplejevid.au.dk (K. Lomborg).
}

- Treatment failure is a major challenge when using noninvasive ventilation.

- Treatment failure directly correlates with a patient's intolerance of non-invasive ventilation.

- Nurses' work experiences play a pivotal role in achieving success with non-invasive ventilation.

\section{What this paper adds}

- A framework for understanding the patterns of nursepatient collaboration to achieve successful non-invasive ventilation treatment.

- Explanations of how nurses adjust to the situation by activating different ways of collaborating. 
- A theoretical contribution to the development of complex interventions in training and education of critical care junior nurses providing non-invasive ventilation.

\section{Introduction}

Treatment failure is a major challenge when using noninvasive ventilation (NIV) for acute respiratory failure (ARF) in patients with chronic obstructive pulmonary disease (COPD). Treatment failure increases mortality, prolongs stays in hospital intensive care units (ICUs) (Lightowler et al., 2003), and correlates directly with patients' intolerance of NIV (Hess, 2011). From a clinical practice viewpoint, a confident and caring nurse may ease a patient's distress, help the patient to gain strength, and motivate the patient to tolerate NIV (Layfield, 2002). To date, there is very little literature on this subject in general. The present paper focuses on the nurse-patient collaboration during NIV, and subsequently discusses how the nurse's collaboration with the patient may influence the success of NIV.

\subsection{Background}

NIV refers to the application of a light mechanically supported mask for ventilation until the patients improve sufficiently to resume spontaneous breathing (Chatburn, 2009). In addition to medical therapy NIV is considered to be standard care for patients with acute respiratory failure (ARF) due to COPD, and its use is increasing (British Thoracic Society Standards of Care Committee, 2002). Unfortunately, the treatment failure rate can be as high as 40\% (Lightowler et al., 2003). Usually, no sedation is needed which means that the patients are capable of providing feedback and elaborating on their experiences and knowledge (Rose and Gerdtz, 2009). In addition, patients can take part in the decisions about their treatment options (Elliott, 2004; Hess, 2011). An Italian study has, however, showed that more than $40 \%$ of the participants never got the opportunity to discuss their NIV treatment, and eighty percent that they were never invited to try another mask (Cabrini et al., 2012).

The success of NIV refers to an initial improvement in physiological and clinical parameters permitting cessation of NIV (Lopez-Campos et al., 2006) and patients' tolerance and cooperation is deemed crucial for the success of NIV (British Thoracic Society Standards of Care Committee, 2002; Pertab, 2009). Patients who experience ARF owing to COPD have severe dyspnoea and may struggle to breathe, and experience anxiety, speaking difficulties, and exhaustion (Brochard et al., 1995; Brochard, 2000). These are potentially challenging complications that could be reduced or avoided by calmly giving the patient clear instructions and information with ample patience and tact (Sawkins, 2001). Nurses are essential for the care and management of patients on NIV because they provide 24-h direct patient care and support, while actively initiating and adjusting their assistance (McBrien et al., 2009; Torheim and Gjengedal, 2010). NIV is, however, a challenge in many respects. Studies report that initiating NIV requires more than twice the workload for the nurse than standard invasive ventilation (Kramer et al., 1995; Nava et al., 1997). Safely caring for these patients requires multiple skills (Nava and Ceriana, 2004) and include choosing the correct interface, handling the equipment, solving problems with mask leaks and pressure lesions, understanding the importance of ventilation settings and comforting the patient during treatment (Gerke and Schmidt, 2011; Nava and Ceriana, 2004). These are all factors that may influence the patient's tolerance of NIV, and are directly related to the experience and competency of the staff performing NIV (Gerke and Schmidt, 2011; Nava and Ceriana, 2004).

Providing comfort and psycho-social support for patients is central to good nursing practice (Benner et al., 2011). Comfort comes from strengthening, aiding, and encouraging as well as soothing and consoling and discomfort and anxiety influence critically ill patients' responses to therapy in a negative way (Benner et al., 2011). Patients with COPD are distressed and often fear the worst (Pertab, 2009) but nurses can improve the ability of COPD patients to cope (Lomborg and Kirskevold, 2005). A prerequisite for an ideal interaction is a common understanding of the patient's condition (Lomborg and Kirskevold, 2005) and seems to be a necessary condition of a successful NIV intervention. There are, however, to our knowledge no studies that address the issue of how nurses and patients with COPD collaborate during NIV, as well as how the collaboration can influence the success of NIV.

\subsection{Objectives}

The purpose of this study is to present a theoretical account of the pattern of nurse-patient collaboration during NIV. The research question guiding the study was "What is the main concern of nurses in relation to the nurse-patient collaboration of NIV, and how do they address this concern?"

\section{Methods}

The study design was classical grounded theory (GT) (Glaser and Strauss, 1967; Glaser, 1978, 1998) adopting a symbolic interactionist perspective, assuming that human beings construct the meaning of reality in interactions with self and others (Blumer, 1986). According to Blumer (1986), any human event can be understood as the result of the people involved continually adjusting what they do in light of what others do. GT is well suited for studying complex processes and is particularly useful for understanding fundamental social-psychological patterns (Glaser, 1978, 1998).

\subsection{Sample and setting}

Concurrent data collection and analysis, constant comparative analysis and theoretical sampling were carried out from December 2009 to January 2012. Data collection and theoretical sampling were accomplished at three Danish hospitals, including three ICUs and one general respiratory ward. We included adult patients with 
ARF due to COPD, and treated with NIV. In accordance with the GT methodology (Glaser, 1978), we used a three-step open, selective and theoretical sampling procedure until conceptual density was achieved. For example, the general ward mentioned above was not included in the open sampling, but because of questions arising in the ICU data, we decided to include the general ward to achieve theoretical sensitivity and saturation. This permitted a theoretical sampling process where the ongoing comparative analysis was guided by increasingly focused data generation (Glaser, 1978). Theoretical saturation of substantive codes was achieved with a total of 21 observations of nurse-patient collaboration (27 nurses) and 11 patient interviews.

\subsection{Data collection and analysis}

Data collection consisted of participant observation of nurse-patient collaboration during treatment and care, and subsequent interviews with the patients. The patient sample was selected to generate variations in age, gender, condition, stage of disease, and length of NIV treatment. The patient participants ranged in age from 43 to 81 years (mean age, 66 years) and the gender distribution was 11 male and 10 female patients. The nurse sample of 27 was selected to generate variation in the nurses' working skills with NIV treatment and care, and ranged from 1 to 15 years of experience. All were registered nurses, and 17 of them were specialists in intensive care nursing. All data were collected by the first author (D.S.). The sessions of participant observation lasted 3-10 h, were repeated when the duration of NIV lasted more than $24 \mathrm{~h}$, and totalled $205 \mathrm{~h}$. The researcher, who is herself a nurse but not employed in the clinical units, took the role of observer. She participated in the care and NIV treatment in a few exceptional cases where she deemed it unethical not to offer momentary assistance. She wore a uniform like the other nurses and moved freely about the ward. During participant observation, she collected data from informal conversations with the nurses. These conversations took place in the ICU and respiratory ward environment during working hours, and lasted between 7 and $50 \mathrm{~min}$. Field notes were taken simultaneously with the observations. Analytical memo writing and analysis, using a constant comparative method and principles of GT (Glaser and Strauss, 1967; Glaser, 1978), began immediately after termination of the sessions. This was necessary preparation to focus the ensuing interview on the observed details, and the theoretical analysis to contextualise the study. The semi-structured interviews with the patients took place at the bedside in the general respiratory ward approximately $24 \mathrm{~h}$ after NIV treatment completion. Unfortunately, not all 21 patients were able to participate in the interview because of poor health or death during or a few hours after treatment completion. The final sample consisted of eleven semi-structured patient interviews. The interviews lasted from 17 to $32 \mathrm{~min}$, and were recorded and transcribed verbatim. The interviews were structured on the basis of data from participant observations, but participants were also encouraged to speak openly about their previous experiences of NIV. Some had reduced memory from the acute phase and some had severe shortness of breath during the interview.

Three questions guided the process of analysis, namely what are the data a study of? Which category does this line or incident indicate? And what is actually happening in the data? Field notes from participant observation and conversations with nurses, transcripts of semi-structured interviews, and theoretical memos enabled rich data about patients' and nurses' collaborative strategies during NIV. The initial data was organised manually, starting with an open line-by-line or segment-by-segment coding analysis of incidents followed by a comparison of open codes (Glaser, 1978) between participant observation sessions and interviews. The coding was carried out by the first author and was supported and discussed with all authors. The analysis was supported by the software programme NVivo 9.0 to systematise the subsequent focused and theoretical coding processes. We performed selective coding (Glaser, 1978) using back and forth techniques, comparing concepts, drawing models of mini theories, and writing more memos until theoretical saturation was achieved and the main concern, succeeding eventually emerged.

In keeping with the principles of GT, the main concern was further explored. On the basis of the evolving analysis and through theoretical sampling, we identified four collaborative typologies and their relationships and variance. The nurses' concern of succeeding with NIV was resolved by the collaborative typologies. Finally, the substantive theory of collaborative typologies was formulated. Participant observation was particularly helpful in enlightening collaborative factors. Moreover, the conversations and interviews offered insight into the nurses and patients' understanding and interpretation, and also the expansion of some patterns of behaviour.

\subsection{Ethical considerations}

The protocol was designed in accordance with the ethical principles of the Helsinki Declaration (World Medical Association, 2002) and was accepted by the Danish Data Protection Agency (J. No. 2009-41-3871). The Regional Research Ethics Committee considered this nonbiomedical project to fall outside the committee's mandate (J. No. 135/2009). According to Danish law (Danish Health Committee, 2010), the professionals selected the patients and sought the initial invitation and the patient's willingness to participate. The managers at the three hospitals were given an oral presentation and written information about the aims and approach of the project, and gave the overall consent for nurses' participation.

\section{Results}

We identified four different types of collaboration and non-collaboration. Each type comprised the following conditions: objectives, understanding the situation, roles in problem identification and conditions for interaction. We labelled the four collaboration typologies: (1) twofold oriented collaboration; (2) well-being oriented collaboration; (3) outcome oriented collaboration; and (4) absent 


\begin{tabular}{|c|c|c|c|c|}
\hline & $\begin{array}{l}\text { Twof old oriented } \\
\text { collaboration }\end{array}$ & $\begin{array}{l}\text { IVell-being oriented } \\
\text { collaboration }\end{array}$ & $\begin{array}{l}\text { Outcome-oriented } \\
\text { collaboration }\end{array}$ & Absent collaboration \\
\hline $\begin{array}{l}\text { Understanding of the } \\
\text { situation }\end{array}$ & $\begin{array}{l}\text { The patient copes well } \\
\text { and the treatment is } \\
\text { effective }\end{array}$ & $\begin{array}{l}\text { The patient is suffering } \\
\text { from discomf ort }\end{array}$ & $\begin{array}{l}\text { There are signs of missing } \\
\text { treatment effectiveness }\end{array}$ & $\begin{array}{l}\text { The nurse feels } \\
\text { inexperienced and } \\
\text { stressed from the } \\
\text { workload }\end{array}$ \\
\hline Objectives & Well-being and outcome & $\begin{array}{l}\text { Well-being (in the } \\
\text { foreground) }\end{array}$ & $\begin{array}{l}\text { Outcome (in the } \\
\text { foreground) }\end{array}$ & $\begin{array}{l}\text { No clear object } \\
\text { (avoid being responsible } \\
\text { for any failure) }\end{array}$ \\
\hline $\begin{array}{l}\text { Roles in problem } \\
\text { identification }\end{array}$ & $\begin{array}{l}\text { Nurse and patient are in } \\
\text { dialogue about the } \\
\text { problems }\end{array}$ & $\begin{array}{l}\text { The nurse meets with the } \\
\text { patient's signs, nonverbal } \\
\text { and verbal } \\
\text { communication about } \\
\text { discomfort }\end{array}$ & $\begin{array}{l}\text { The nurse responds to and } \\
\text { communicates problems } \\
\text { of missing treatment } \\
\text { effect }\end{array}$ & $\begin{array}{l}\text { No communication about } \\
\text { problems } \\
\text { Exchange of information }\end{array}$ \\
\hline \multirow[t]{2}{*}{ Interaction } & $\begin{array}{l}\text { Common knowledge } \\
\text { sharing }\end{array}$ & $\begin{array}{l}\text { Share the patient's } \\
\text { knowledge of well-being }\end{array}$ & $\begin{array}{l}\text { Share the nurse's } \\
\text { knowledge of treatment } \\
\text { effectiveness }\end{array}$ & No knowledge sharing \\
\hline & $\begin{array}{l}\text { Encouraging the patient to } \\
\text { continue in the same } \\
\text { (good) way }\end{array}$ & $\begin{array}{l}\text { Accommodating and } \\
\text { supporting (aid, comfort) } \\
\text { the patient to optimise } \\
\text { well-being }\end{array}$ & $\begin{array}{l}\text { Directing and instructing } \\
\text { the patient to provide } \\
\text { better conditions for } \\
\text { ventilation }\end{array}$ & $\begin{array}{l}\text { Depersonalising the } \\
\text { patient to work in peace }\end{array}$ \\
\hline
\end{tabular}

Fig. 1. Collaboration typologies.

collaboration. A change in the patient's condition could involve a shift in the collaboration typology. For example, when a patient who experienced discomfort and no benefit from the treatment began to benefit from the treatment, it would typically result in a shift in the nurse's way of collaborating with the patient. This type of shift appeared as a sliding transition between the collaboration typologies.

Fig. 1 shows the conditions for the four collaboration typologies; twofold oriented collaboration, well-being oriented collaboration, outcome oriented collaboration, and absent collaboration.

\subsection{Twofold oriented collaboration}

In the twofold oriented collaboration, the nurse and patient collaborated to maintain tolerance by optimising comfort and the treatment effect to achieve success with NIV. The nurses worked simultaneously with a patientcentred and treatment-effective approach to nursing care. Thus, the substance in the nurse-patient collaboration had a twofold focus. A study nurse expressed the duality this way:

If a patient is uncomfortable or expresses a need, it's important that you include tending to that as a part of your responsibilities in NIV treatment. If the patient has trouble breathing, you should always take it seriously, no matter what, or the treatment might end in failure due to the patient being unable to tolerate it (8)

The patients in this typology experienced the treatment as being beneficial (their breathing improved) and they usually accepted and coped very well with NIV. Their contributions during the treatment were central despite the vulnerability caused by their current health condition.
They contributed by giving feedback on their concerns, needs, and preferences throughout the NIV treatment, and by applying knowledge from their living with COPD.

The nurses accomplished patient-centred care and treatment measures with confidence. This confidence seemed to be based on experience, and was performed patiently and calmly. The nurses and patient's viewpoints and preferences were united through dialogue in the caring process. Accordingly, their communication was based on knowledge sharing. Participant observation field notes exemplify this:

The nurse says that she would like the patient to sit upright, as it's good for his lungs, "Are you okay with that?" "Yes" the patient agrees. The nurse helps the patient into a more upright position. The hospital bed is supporting the patient's knees and elevated in the upper section. The patient replies that he doesn't want pillows under his arms, and that he wants them to hang over the cot sides of the bed. The nurse nods understandingly (13)

The specific starting point for problem-solving was either defined by the patient or the nurse. The starting point could be when to have a mask-break to drink, eat, or communicate. It could also be about discomfort, how to be positioned, how to solve mask fitting problems, patientventilator asynchrony troubles, or about increasing pressure support. All this communication focused on how to maintain success by optimising comfort and improving effectiveness in the process of achieving success with NIV. Furthermore, this process was supported by the nurses' encouraging responses to the patients' way of managing NIV. Participant observation field notes give an example of a nurse's encouraging response: 
"The mask is very tight and so hot, and the air comes out so terribly fast," says the patient. The nurse answers, "Yes, that's true," and adds that she can turn down the temperature of the humidifier and open the window. The patient nods, satisfied, as the nurse replies, "I think you are doing very well so maybe it's time for a short break soon" (13)

\subsection{Well-being oriented collaboration}

In the well-being oriented collaboration, the nurse and patient collaborated to improve the patients' well-being and tolerance of NIV to achieve success. This was necessary because of the patients' severe difficulties in coping with the ventilation and the side effects of it (breathlessness, thirst, exhaustion, sleeplessness, heat, noise, mask discomfort, communication difficulties). Since the patients' discomfort from was the most urgent problem, patient-centeredness became the primary approach in nursing care to achieve tolerance of NIV. The nurse therefore accepted that the focus on treatment effect was given lower priority for a period. The substance in the nurse-patient collaboration was a concern for the patient's discomfort. A nurse expressed some of the challenges with the patients' discomfort in this way:

As a nurse, you can also get a little scared, especially if you are not good at relaxing and do some of the things the patient wants to do... and reap the benefits of it in that way. You have to accept a delay in the effect of NIV when discomfort is the main problem, but it takes a lot of experience to do so and to know it can be useful. For example, accept many short breaks (17)

Patients in the well-being oriented typology struggled with breathlessness and discomfort and experienced little (or no) benefit from the treatment. The patients had little faith in NIV and tried to avoid the mask. The nurses were aware of their concern about this and of the consequences. A study nurse expressed a dilemma between intolerance and treatment effect this way:

Even when you can see that the saturation will drop after removing the mask for a short break, you sometimes have to take that risk and hope that the patients realise that their shortness of breath is even worse without the mask (14)

In this typology, the nurses accommodated and patiently supported the patients to fulfil their needs and complying with preferences to improve their tolerance of NIV. To meet needs and preferences, the nurses also responded to the signs and nonverbal communications of discomfort with individual support, aid and comfort as the participant observation field notes exemplify:

The patient indicates with body language that she wants to lie down on her side [again]. She has been sitting on the bedside for less than five minutes. The nurse asks if it is too strenuous and the patient nods. Then the patient tells the nurse [by shaking her head] that she doesn't want all the pillows on the bed. The nurse asks if she is too hot, and suggests a blanket instead of the duvet. The patient nods appreciatively and asks for water by pointing at the empty glass on the bedside table... (13)

As indicated in the field note, the patients set the agenda by expressing their discomfort, needs and preferences. Accordingly, the substance of the nurse-patient collaboration is to optimise the patients' comfort to achieve tolerance of NIV. One nurse reflected on her priorities after a day-shift:

Well, there were some things that I didn't manage to do today, which I would like to have done, but they got lower priority because my patient had other needs and they were prioritised (11)

Another concern from the nurse's perspective was related to the patients' general health. When a patient had severe end-stage COPD, the focus was on patient comfort and this approach did not include expectations for objective treatment effect. NIV was usually well tolerated by patients at this stage owing to severe breathlessness, and sparse mental and physical strength. The success of the NIV was adjusted to palliation.

\subsection{Outcome-oriented collaboration}

In the outcome-oriented collaboration, the nurse and patient collaborated to improve the patients' benefit of the treatment (improve breathing). It was recognised as the most urgent problem, and mainly communicated by the nurses. The patients followed the nurses' advice to improve their health condition, since the nurse regarded it to be under threat or out of control. Participant observation field notes illustrate how a nurse set the agenda and took control:

The nurse tries to start-up NIV, but the patient [insistently] talks about her swollen legs. Her lips are slightly cyanosed and she is very short of breath. The nurse politely cuts off the patient, and says that she should put the mask on now... (6)

The nurses in the outcome-oriented typology typically gave the patients' preferences lower priority in favour of the patient's health and safety. Nursing appeared to be performed with a confident and skilled know-how approach to obtain treatment effect and success with NIV. One nurse reflected on what it takes to manage this type of situation:

It's very important that we [nurses] get a lot of experience managing different situations, so we can compare them. We can then judge when the situation is critical and take over or do something, even if the patient is reluctant (17)

The patients usually resign and feel relieved when the nurse 'takes control', meaning that nurses gave the patients instructions and directions on how to breathe and wear the mask to enhance the ventilation and succeed with NIV. Participant observation field notes exemplify one nurse's instructions: 
The patient is talking to a relative while wearing the mask and, subsequently, the nurse says to the patient, "You need to concentrate your energy on breathing deeply into your lungs instead of talking; otherwise the mask will leak too much" (14)

The directions were also employed to prevent patientventilator asynchrony. A study nurse expressed the importance of good ventilation conditions:

"I keep on telling him [the patient] to breathe 'normallý. As soon as he does, everything goes well. If he forgets it, he often breathes too fast. This leads to discomfort because the machine has difficulty synchronising with the rapid breathing" (5)

Furthermore, the nurse aimed to solve the problems with patient-ventilator asynchrony, mask leaks, ventilation mode, and settings, and worked continuously on titrating NIV from the results of the blood gas analysis. The outcome-oriented collaboration was characterised by the nurse's concerns for the patients' health and safety. This concern was resolved by both the advice to change behaviour and the by technical adjustments in the ventilation. The overall purpose was to obtain treatment effect on the laboured breathing to achieve tolerance and succeed with NIV.

\subsection{Absent collaboration}

In the typology of absent collaboration, the nurses' and patients' concerns were divergent, with embedded potential conflicts, and they did not collaborate to reach common solutions. The patients' aim was to feel comfortable and improve with their breathlessness, whereas the nurses' aim was to avoid being personally responsible for any kind of failure. The nurses followed procedural accounts and well-known methods, and took no chances. 'Not taking chances' is exemplified by the following participant observation field note:

The patient says something that the nurse cannot hear. The patient grabs the bedrails, and pushes the duvet away. The nurse asks whether it is too hot, but that is not it. The patient shakes his head and tries to say something else. It sounds as though he wants to get up and out of the bed. So the nurse replies that it is too dangerous [the patient has to stay in bed]. The patient shakes his head energetically and rips the mask off and says breathlessly, "it's too hard lying down... I need to stand up" (16)

The patients try to become involved in their own care and to contribute with their experience from living with COPD. But the nurses did not manage to meet the patients' desire for involvement, which could be interpreted as depersonalisation of the patients. Participant observation field notes exemplify how a nurse was busy solving clinical and documentation tasks and did not manage to pay attention to the patient:

The patient attempts to say something while the nurse is standing by a table at the end of the bed. His voice is weak and he has difficulty breathing, and seems to be uneasy. The nurse says that she can't understand what he is saying [due to the mask]. She doesn't look up or ask again. She continues the clinical work; IV-infusion, medication, documentation, titration, etc. (20)

This nurse-patient interaction was characterised by distance and a superficial connection. Hence, the nurses did not invite the patient to give feedback on his or her concerns, needs, or preferences during the NIV treatment. Nor were patients invited to apply knowledge about what usually works in their daily life with COPD and there was no communication about concerns.

In the absent collaboration, the nurses seemed to experience stress and this influenced the nurse-patient interaction unfavourably. The nurses were feeling stressed due to the workload of monitoring and titrating treatment and dealing concurrently with patient involvement aspects, such as fulfilling needs, complying with preferences, and the patient's concerns. A nurse expressed her feelings about the workload:

I mean, the [NIV] patients follow everything I do, and when I'm standing next to the patients they always ask me to do something. First it is something with the mask, then they are thirsty, then they want to sit upright, or lie down, then they want to listen to the radio, and then they don't. Yes, it is like that all day, and I don't always manage to get all my work [clinical and technical] that I should be doing, done; that's what stresses me (17).

This quotation also illustrates how the nurse was uncertain and inexperienced in handling his or her double focus on patient comfort and treatment effect. The nurses in absent collaboration typology typically reduced complexity to succeed with NIV. NIV treatment and care resulted in an inflexible and impersonal approach towards the patient. Participant observation field notes exemplify this:

The patient almost powerlessly fumbles with his hand around the area where the Velcro strap is tightened over the ear. "No", says the nurse in a strict voice, and takes his hand down, "You must keep the mask on". The nurse adjusts the mask. The patient tries to say something, but he has little power to speak, so the sound he makes is very weak, and it is almost drowned by the noise from the ventilator. The nurse continues with her other tasks (5).

\section{Discussion}

In this grounded theory study, we investigated significant patterns of nurse-patient collaborations during NIV treatment for patients admitted to the hospital with ARF due to COPD. We show how the nurses' behaviour and activities are related to a main concern of succeeding with NIV and how four different ways of collaboration and noncollaboration resolve the nurses' concern. Likewise, that providing patient-centred care while setting up and maintaining acute NIV is complex. The complexity arises from the dualism of care and cure and from the nurses' 
constant adjustment to the patients' condition. Providing quality care and handling the intervention is central for nurses. Nevertheless, some nurses find it challenging to comfort, strengthen, support and encourage the patient while simultaneously handling the equipment, monitoring, titrating, and troubleshooting the treatment. Morse (1991) found that the relationship between the nurse and the patient may be either mutual or unilateral. She identified four types of mutual relationships that depended on circumstance as length of time together, needs, desires and personality factors. In the unilateral relationship, there was asynchrony between the nurse and patient with one person unwilling or unable to develop the relationship.

In the typology of absent collaboration, we found that the nurses are stressed due to lack of experience with NIV, the workload and challenges, which unfavourably influence the nurse-patient collaboration to achieve positive outcome of NIV. These findings are in line with the British Thoracic Society Standards of Care Committee of NIV (2002), which recommend that nurses should be carefully trained in NIV applications and estimate that to retain their skills and become experienced, nurses should take care of at least one patient per month. Success rates of NIV are influenced by many factors, among which training and experience is a key (Nava and Ceriana, 2004). Furthermore the use of NIV by inexperienced personnel leads to high treatment failure rates (Lopez-Campos et al., 2006). Our findings illustrate how nurses in the typology of absent collaboration felt uncertain and inexperienced in handling the double focus on patient comfort and treatment effect to achieve tolerance and success with NIV. Consequently, NIV treatment and care can result in an inflexible and impersonal approach towards the patient.

We found that the twofold oriented, well-being oriented and outcome-oriented collaboration typologies are different ways of collaborating. In these three typologies, the nurse and patient collaborate to achieve success with NIV. The nurses also demonstrate that they have a broad and complex understanding of successfulness as a patient-experienced improvement combined with objective health improvement. Parallels can be drawn to Benner et al.'s (2011) finding that discomfort and anxiety influence critically ill patients' response to therapy. According to these authors, comfort is "to strengthen, aid, and encourage as well as to soothe and console, and offering comfort measures to the patient requires that the nurse perceives that comfort is needed" (p. 215). Comfort, they state, can mean many different things to different people in different situations, but is a central notion of the good that guides the nurse-patient relationship (Benner et al., 2011).

Our study shows that the nurses were aware of the correlation between tolerance of NIV and the patients' experience of treatment effect on breathlessness, discomfort, and nurse-patient collaboration. Hill (2011) has a definition of reasons for treatment failure and points to three separate reasons for failure: environmental, patient-related, and technical factors, but adds that the specific reason for failure can be identified only after failure has occurred. Hill (2011) addresses intolerance as a patient-related factor like discomfort, claustrophobia, agitation, and progression of underlying disease. This definition could imply that patients' inability to tolerate NIV is an isolated reason for failure. Our study illustrates how nurses interpret intolerance as a result of a patient's experiences of (lack of) treatment effect on the breathlessness and discomfort from the NIV side effects.

We found that the nurse-patient collaboration entails a mutual understanding of the situation, of the objectives and problem-identification roles. Furthermore, that the nurse-patient collaboration is build on knowledge-sharing and the nurse's attentive response to the patient. Waterworth and Luker (1990) refer to nurse-patient collaboration in terms of patient involvement, and patient participation in decisions that affect the patients' health and well-being. The advantages of the collaboration have been described by Ashworth et al. (1992) as increased patient satisfaction, improved compliance and the enhancement of human dignity.

There are limitations in this study. The recruitment was limited to COPD patients with ARF admitted to the ICU and general respiratory wards of three hospitals in Denmark. Using the grounded theory methodology, we cannot assume that the findings reflect all details of the entire ranges or approaches, behaviours, and strategies among COPD patients with ARF who are on NIV treatment. For example, it is possible that international NIV collaborative practices differ because of cultural differences.

The quality of grounded theories should be assessed by the criteria fit, work, relevance, and modifiability (Glaser, 1978; Lomborg and Kirkevold, 2003). The subject under study was specifically defined and the analysis completed to theoretical saturation. The findings contribute to the predictions and explanations of the important factors of nurse-patient collaborations required to achieve success with NIV. We therefore maintain that our empirically warranted interpretation of the nurses' main concern about the collaboration and how that concern is resolved is relevant when understanding the complexity of tolerance and NIV success. We believe that our theoretical account fits the overall realities of current nurse-patient collaborations during NIV treatment in Denmark and culturally comparable countries, although we expect it would require modification to reflect changes in the organisational settings of NIV treatment. The theory is an integrated set of hypotheses about important factors present in the nurse-patient collaboration with regards to NIV management. Our theoretical account is relevant for nurses who provide care and who monitor NIV.

\section{Conclusion}

In this article, we demonstrate the significance of the nurse-patient collaboration during NIV and this hypothesis must be further tested. We offer a theoretical supplement to the development of complex interventions for increasing evidence (Campbell et al., 2000; Forbes, 2009) on nurse-patient collaboration. Raising awareness of the challenges associated with this particular treatment may be useful for clinical nurses who encounter the challenges that this particular treatment involves. 
Based on the discussion and our findings, we suggest that clinicians should increasingly include nurse-patient collaborative aspects in the use of NIV and in the training of junior nurses. We suggest that future research projects should investigate the effect of patient-nurse collaborative typologies to increase our knowledge of how to influence tolerance and succeed with NIV. Furthermore, we suggest an educationally complex intervention for junior nurses to measure whether or not it is possible to escalate the junior nurses' experiences. For example, a complex intervention could be a combination of learning from authentic videobased supervision, problem-based mannequin simulation, hands-on training, and theory.

\section{Acknowledgements}

The authors are grateful to all patient participants, without whom this work would not have been possible. We would like to acknowledge the support of staff working at the ICUs of Randers Regional Hospital, Aarhus University Hospital, and Sydvestjysk Hospital, and the general respiratory ward of Sydvestjysk Hospital, Denmark.

Contributions: Dorthe Sørensen alone has done the data collection work, but endeavoured study design and manuscript preparation works by teaming with Kirsten Frederiksen, Thorbjoern Groefte and Kirsten Lomborg.

Conflicting of interest: The authors declare no conflicts of interest with respect to the authorship and/or publication of this article.

Funding: This project was funded by the Faculty of Health Sciences at Aarhus University, the Regional Hospital of Randers, and the Danish Council for Independent Research.

Ethical approval: The protocol was designed in accordance with the ethical principles of the Helsinki Declaration (World Medical Association, 2002) and was accepted by the Danish Data Protection Agency (J. No. 2009-413871). The Regional Research Ethics Committee considered this non-biomedical project to fall outside the committee's mandate (J. No. 135/2009).

\section{References}

Ashworth, P.D., Longmate, M., Morrison, P., 1992. Patient participation: its meaning and significance in the context of caring. Journal of Advanced Nursing 17 (12), 1430-1439.

Benner, P., Kyriakidis, P.H., Stannard, D., 2011. Clinical Wisdom and Interventions in Acute and Critical Care: A Thinking-in-action Approach, 2nd ed. Springer, New York.

Blumer, H., 1986. Symbolic Interactionism: Perspective and Method. University of California Press, Berkeley, CA.

British Thoracic Society Standards of Care Committee, 2002. Non-invasive ventilation in acute respiratory failure. Thorax 57 (3), 192-211.

Brochard, L., 2000. Non-invasive ventilation for acute exacerbations of COPD: a new standard of care. Thorax 55 (1), 817.

Brochard, L., Mancebo, J., Wysocki, M., Lofaso, F., Conti, G., Rauss, A., Simonneau, G., Benito, S., Gasparetto, A., Lemaire, F., 1995. Noninvasive ventilation for acute exacerbations of chronic obstructive pulmonary disease. New England Journal of Medicine 333 (13), 817-822.

Cabrini, L., Moizo, E., Nicelli, E., Licini, G., Turi, S., Landoni, G., Silvani, P., Zangrillo, A., 2012. Non-invasive ventilation outside the intensive care unit from the patient point of view. A pilot study. Respiratory Care 57 (5), 704-709.
Campbell, M., Fitzpatrick, R., Haines, A., Kinmonth, A.L., Sandercock, P., Spiegelhalter, D., Tyrer, P., 2000. Framework for design and evaluation of complex interventions to improve health. British Medical Journal 321 (7262), 694-696.

Chatburn, R.L., 2009. Which ventilators and modes can be used to deliver noninvasive ventilation? Respiratory Care 54 (1), 85-101.

Danish Health Committee, 2010. Danish Health Law.

Elliott, M.W., 2004. The interface: crucial for successful noninvasive ventilation. European Respiratory Journal 23 (1), 7.

Forbes, A., 2009. Clinical intervention research in nursing. International Journal of Nursing Studies 46 (4), 557-568.

Gerke, A.K., Schmidt, G.A., 2011. How to set up an acute non-invasive ventilation service. In: Elliott, M.W., Nava, S., Schönhofer, B. (Eds.), Non-invasive Ventilation and Weaning: Principles and Practice. European Respiratory Society, p. 87.

Glaser, B.G., 1978. Theoretical Sensitivity: Advances in the Methodology of Grounded Theory. Sociology Press, Mill Valley, CA.

Glaser, B.G., 1998. Doing Grounded Theory: Issues and Discussions. Sociology Press, Mill Valley.

Glaser, B.G., Strauss, A.L., 1967. The Discovery of Grounded Theory: Strategies for Qualitative Research. Aldine de Gruyter, Chicago, IL.

Hess, D.R., 2011. Patient-ventilator interaction during noninvasive ventilation. Respiratory Care 56 (2), 153-165.

Hill, N.S., 2011. Troubleshooting non-invasive ventilation. In: Elliott, M.W., Nava, S., Schönhofer, B. (Eds.), Non-invasive Ventilation and Weaning: Principles and Practice. European Respiratory Society, p. 478.

Kramer, N., Meyer, T.J., Meharg, J., Cece, R.D., Hill, N.S., 1995. Randomized, prospective trial of noninvasive positive pressure ventilation in acute respiratory failure. American Journal of Respiratory and Critical Care Medicine 151 (6), 1799.

Layfield, C., 2002. Non-invasive BiPAP - implementation of a new service. Intensive and Critical Care Nursing 18 (6), 310-319.

Lightowler, J.V., Wedzicha, J.A., Elliott, M.W., Ram, F.S., 2003. Non-invasive positive pressure ventilation to treat respiratory failure resulting from exacerbations of chronic obstructive pulmonary disease: Cochrane systematic review and meta-analysis. British Medical Journal 326 (7382), 185

Lomborg, K., Kirskevold, M., 2005. Curtailing: handling the complexity of body care in people hospitalized with severe COPD. Scandinavian Journal of Caring Science 19 (2), 148-156.

Lomborg, K., Kirkevold, M., 2003. Truth and validity in grounded theory a reconsidered realist interpretation of the criteria: fit, work, relevance and modifiability. Nursing Philosophy 4 (3), 189-200.

Lopez-Campos, J.L., Polo, C.G., Jimenez, A.L., Arnedillo, A., Gonzalez-Moya, E., Berni, J.J.F., 2006. Staff training influence on non-invasive ventilation outcome for acute hypercapnic respiratory failure. Monaldi Archives for Chest Disease 65 (3), 145.

McBrien, B., Reilly, R., Wynne, C., 2009. Non-invasive ventilation: a nurseled service. Emergency Nurse: The Journal of the RCN Accident and Emergency Nursing Association 17 (6), 30-35.

Morse, J.M., 1991. Negotiating commitment and involvement in nursepatient relationship. Journal of Advanced Nursing 16 (4), 455-468.

Nava, S., Ceriana, P., 2004. Causes of failure of noninvasive mechanical ventilation. Respiratory Care 49 (3), 295-303.

Nava, S., Evangelisti, I., Rampulla, C., Compagnoni, M.L., Fracchia, C. Rubini, F., 1997. Human and financial costs of noninvasive mechanical ventilation in patients affected by COPD and acute respiratory failure. Chest 111 (6), 1631.

Pertab, D., 2009. Principles of mechanical ventilation - a critical review. British Journal of Nursing 18 (15), 915-918.

Rose, L., Gerdtz, M., 2009. Non-invasive mechanical ventilation in Australian emergency departments: a prospective observational cohort study. International Journal of Nursing Studies 46 (5), 617-623.

Sawkins, D., 2001. Non-invasive positive pressure ventilation. Nursing Times 97 (26), 52-54.

Torheim, H., Gjengedal, E., 2010. How to cope with the mask? Experiences of mask treatment in patients with acute chronic obstructive pulmonary disease-exacerbations. Scandinavian Journal of Caring Sciences 24 (3), 499-506.

Waterworth, S., Luker, K.A., 1990. Reluctant collaborators: do patients want to be involved in decisions concerning care? Journal of Advanced Nursing 15 (8), 971-976.

World Medical Association, 1964-2002. World Medical Association Declaration of Helsinki: Ethical Principles for Medical Research Involving Human Subjects. World Medical Association, Ferney-Voltaire. 